\title{
SOME ASPECTS OF THE CONSERVATIVE TREATMENT AND PREVENTION OF LUMBAR DISC DISEASE
}

\author{
Mariyana Mihajlova $^{1}$, Silviya Filkova ${ }^{2}$,Vesselina Michaleva ${ }^{3}$ \\ ${ }^{1}$ Department of Physiotherapy, Rehabilitation, Thalassotherapy and Occupational \\ Diseases, Faculty of Public Health, Medical University of Varna \\ ${ }^{2}$ TRS of Rehabilitation Therapist, Medical College, Medical University of Varna \\ ${ }^{3}$ Department of Anatomy, Histology and Embryology, Faculty of Medicine, \\ Medical University of Varna
}

\begin{abstract}
INTRODUCTION: Lumbar disc disease is a degenerative disease of the intervertebral discs of the spine. It usually affects the lower portion of the spine.

AIM: To summarize the main physiotherapeutic approaches for prophylactic and treatment of the lumbar disc disease.

MATERIALS AND METHODS: Analysis of literary sources.

RESULTS: There is a significant link between disc degeneration and lower back pain. The first group of complaints is more and more common in young people between 20 and 30 years of age.

CONCLUSION: An adequately conducted treatment and prophylactic measures have a big impact when it comes to improving the quality of life of the patients.
\end{abstract}

Keywords: disc disease, properly timed treatment, prevention

\section{INTRODUCTION}

The degeneration of the intervertebral discs is thought to be the first degenerative change affecting the structures of the spine and it usually is followed by a development of spondylolysis, spondyloarthrosis and stenosis of the spine $(10,11)$. The most affected by the process are the cervical and lumbar regions of the spine, because of their anatomic and functional features. The lumbar region in particular is affect-

\footnotetext{
Address for correspondence:

Mariyana Mihajlova, MD, PhD

Clinic of Physical Therapy and Rehabilitation,

St. Marina University Hospital

1 Hristo Smirnenski Blvd, 9010 Varna

e-mail:m.mihailova96@abv.bg
}

ed in $20 \%$ to $83 \%$ of the cases of disc pathology during the different stages of life (31).

The lumbar region is considered to be the main backbone of the spine and in daily life it is exposed to significant loads of the order of hundreds of kilograms. This is one of the main reasons for early disc damage and manifestation of the lumbar disc disease (LDD) $(1,25)$. Disc degeneration is considered one of the main causes of pain in the lower back $(27,29)$. The analysis of the medical literature shows that nowadays younger and younger people, between 20 and 30 years of age, are affected by the disease, which has a big chance of relapse $(7,8,21)$. The chronical course of the disease leads to long-lasting disability, development of physical, psychicological and social disadaptation. This leads to the need for more effec- 
tive methods of treatment and prevention (23). The good understanding of the mechanisms, leading to disc degeneration, can contribute to better therapeutic strategy for prevention and control of the disease.

The main factors in the pathogenesis of lumbar disc disease (LDD) are:

$\diamond$ Genetic predisposition

$\diamond$ Trauma (micro trauma)

$\diamond$ Static and dynamic load of the spine

$\diamond$ Congenital or acquired anomalies of the spine

$\diamond$ Overweight etc.

Degenerative changes in the intervertebral discs occurring with age cause curvature of the spine, deformation of particular vertebras, and development of osteophytes. The ligaments of the spine providing the spinal mobility and strength, calcify $(8,10)$. The excess physical loads alongside the already existing degenerative changes can be a trigger mechanism for a widespread clinical case of compressive nerve syndrome.

Taking into account the modern views regarding the pathogenesis of disc disease, we consider that the proper approach may slow down the progression of the disease and improve the long-term forecast for the patients' future.

The number of patients suffering from LDD in the last few years has grown. It is also worrying that the relative share of the affected individuals in active age is significant. In a demographic research among 120 people suffering from LDD, the following incidence based on age was found: $23 \%$ of the people were between 20 and 29 years of age, $29 \%$ - between 30 and 39, 31\% ranged between 40 and 49 and the remaining $17 \%$ were $50-60$. It is also worrying that a lot of those people $-38 \%$ were conducting mainly medicated treatment. As a main reason for this they name the lack of information about physiotherapeutic treatment as well as the lack of time because of their professional engagements. This focused our attention on the problem. We gathered and summarized the existing data regarding the main conservative and therapeutic approaches and methods for prevention from the leading literature sources.

The goal of this overview is to summarize the main physiotherapeutic methods for prevention and treatment of lumbar disc disease.
Main Stages of the Conservative Treatment of LDD

The modern treatment requires complex approach, consistent with the stage of the disease and its clinical manifestations. The core principles that the conservative treatment follows are:

1. cupping for the pain syndrome;

2. removal of muscle imbalance;

3. improvement of the blood flow of the roots of the spinal cord;

4. normalization of the nerve conductivity of the affected roots;

5. removal of the connective tissue expansions;

6. building back the proper posture via exercises;

7. cupping for the psycho-somatic disorders.

\section{Medicated Treatment}

The resources for the beginning of the treatment include: analgesic drugs, NSAIAs - nonsteroidal anti-inflammatory agents, corticosteroids, myorelaxants, and vitamin B. They are required and irreplaceable for the complex treatment especially in periods of exacerbation. The medicaments are important in order for the inflammation and the swelling of the tissue to be contained and the pain to be suppressed $(7,10)$. In very rare cases of a relapse it is possible for the treatment to begin with physical means.

\section{Treatment with Physical Factors}

Physical rehabilitation is a mandatory measure of the complex methods for recovery of the patients suffering from lower back pain and has to be included as early as possible in order to prevent long-lasting disability in such cases (36). Physical rehabilitation is unique not only because of its mechanism, but also because it can be applied locally onto the place of the affected spinal motor segment.

The physical factors that are being used for treatment of disc disease include physiotherapy using special apparatuses, hydrotherapy, heat therapy (mud therapy, paraffin therapy), passive and active kinesitherapy, etc. $(2,5,9)$. They provide the opportunity for direct anesthesia via reducing the hypertonia of the paravertebral musculature, blocking the pain nociception, the anti-inflammatory effect of the joint and ligamentous apparatus of the spine and enhancing the processes of reinnervation. The positive effect on the patient is proven in various studies $(18,33)$. 
Mariyana Mihajlova, Silviya Filkova,Vesselina Michaleva

In the very beginning of the exacerbation of the disease with signs of prominent pain syndrome, the proper conditions for optimal relaxation and rest of the affected portion of the spine need to be created. This is done by positional therapy - the so-called Williams lumbar flexion and wearing a corset $(5,6)$. Through these measures improvement of the blood flow of the affected segment, muscle relaxation, removal of the compressive occurrences regarding the neurovascular structures and pain reduction are achieved.

The therapeutic program has to be separate and individually made for every patient and it is usually a result of a collaboration between a physiotherapist, a neurologist and in some cases - a neurosurgeon. The therapy of the disc disease begins with medicated treatment and later on, at the proper stage, physiotherapeutic means are included. This is especially relevant in the acute phase. Physical medicine can also be used as a preventative measure and in this pathology 3 to 4 courses are recommended yearly $(2,5,9)$.

Physical therapy with its prophylactic and healing properties can contribute to lengthening the periods of remission, lowering the risk of new relapses and rapid progression of the disease as well as conserving the functional capacity of the patients. From an economic efficiency perspective this treatment has an important place in this pathology.

\section{Prevention of Lumbar Disc Disease}

Prevention has a significant role in lowering the number of relapses of the disease and improving the quality of life of the patients. It includes:

Fighting back obesity - excess weight is a huge problem in today's society. The structures of the spine and more specifically the lumbar region and the lower limbs are exposed to constant mechanical stress from the excess weight, which leads to premature degenerative changes (30). Maintaining optimal body mass is crucial.

Physical exercises have proven their place in the prevention and maintenance of a properly functioning musculoskeletal system. Regular sport activities build proper posture habits and strong muscle corset provides a base for strong spine. The individually made programs with remedial and physical exercises have a proven effect in controlling the lower back pain $(4,35)$.
Alternative therapies - yoga therapy. The spine is one of the main focuses of yoga therapy. The emphasis is on the flexibility and strength which contribute to the fast suppression of the pain. This method is gaining more and more proponents and, when properly executed, gives good results (32).

Healing massage. It has a beneficial effect on the central neurous system, the mechanisms of neuro-humoral regulation and neuromuscular apparatus. It helps muscle relaxation, balances the excitatory inhibitory processes, improves the biomechanics of the spine and the sleep quality. The purposeful prophylactic application of remedial massage is also an effective measure in managing lower back pain $(3,14)$.

Prophylactic of spinal injuries. It aims towards prevention of a direct trauma in everyday life and during physical exercises. After each trauma a nidus of aseptic inflammation emerges which is a premise for development of an early degenerative process. Many authors point the mechanical factor as a leading one in the pathogenesis of the disc disease. They link the prolonged impact on the spine or the separate motor segment with the increased static or dynamic load, leading to traumas in the intervertebral discs and other structures $(15,37,38)$.

Prophylactic of stress situations. Stress is a trigger mechanism for developing most of the known diseases. Diseases of the skeleton are not an exception. More and more authors emphasize the need of psychotherapy as a part of the complex treatment of disc disease $(19,20)$.

Rejecting bad habits. A growing number of authors emphasize the fact that alcohol and smoking have a negative impact over both the anabolic processes in the body and recovery after the clinical manifestation of the disease $(16,28)$.

Hygiene of labor - ergotherapy. The creation of a suitable working environment or the so-called ergonomics of the office desk is of a great significance when it comes to preventing relapses of LDD. This includes using ergonomic chairs when working on a desk, and lower back stretching every 45-60 minutes. The chair has to be comfortable and its back has to fit perfectly the individual's back. People who are have a physical job should keep a proper stance when lifting heavy objects as well as maintain a prop- 
er posture while walking (17). The harmonic combination of work and rest is a key factor for the proper functioning of the spine (1).

Hygiene of sleep. Orthopedic mattress and pillow are required in order to maintain the physical curves of the body and not to create conditions for muscle imbalances and blockage of the intervertebral joints (22).

The application of chondroprotectors. The supplements containing chondroitin sulphate, glucosamine sulphate and collagen used widely in the last years in the prevention of osteoarthritis. On one hand they have a symptom-modification effect i.e. reduce the pain and support the improvement of the functions of the joints and the back, on the other hand, they have a structure-modification effect because they hold or stop the progression of the degenerative-dystrophic process $(13,24,34)$.

Back education program. This education program has as a goal to provide practical information regarding the posture, biomechanics of the body, adopting exercises to keep the back in good condition having as a main goal the long-term prevention of pain. The studies in this direction show that the back education program can gave a positive effect and enhance the recovery $(12,26)$.

$\diamond$ Relax your spine and don't sit for long or remain static.

$\diamond$ Train your spine and keep it stable.

$\diamond$ Correct your posture and keep it balanced.

$\diamond$ The comfortable sitting leads to disc herniation. The so-called dynamic sitting is recommended.

\section{DISCUSSION}

The active way of life is the core of the physical and mental health of the individual.

Lower back pain is a common reason for reducing physical activity and development of depression, which deepens the already existing problem and creates a vicious circle that is hard and time-consuming to break. This requires a serious and analytical approach to the treatment and prevention of disc disease in order to reduce the relapses and to ensure a better quality of life for the patients. The doctor of physical and rehabilitation medicine and the kinesitherapist have a key role in the creation of a complex treatment algorithm and its practical applica- tion. There is a need for professional collaboration with neurologists, neurosurgeons and orthopedists treating such patient for the first time. Their timely inclusion, consistent with the stage of the disease is a premise for faster recovery and prevention of complications. The regular conduction of prophylaxis courses of physiotherapy outside the paroxysmal period is a guarantee for maintaining the spine in good condition. This would limit significantly the frequency of the relapses. The distribution of information brochures regarding the main principles of the hygiene of labor and rest in those patients would be a good prophylactic measure.

\section{REFERENCES:}

1. Getchev J. Fundamentals of total vertebrology. Acad. publishing „Prof.Marin Drinov“. Sofia: Vion; 2002 (in Bulgarian).

2. Yoshinova-Koleva I, Modern methods of neurorehabilitation. Sofia: RIK „Simela”; 2007 (in Bulgarian).

3. Kraev T. Textbook in therapeutic massage and relaxation positometric common part. Sofia: Veridia; 2005 (in Bulgarian).

4. Kostadinov D. Lumbar-sacral syndrome. Sofia: MF Sofia; 1983 (in Bulgarian).

5. Kostadinov D, Nikolova, Bank C, Sunny P. Physical factors in the complex treatment and rehabilitation of some common diseases. In: Physics. Sofia; 1975 (in Bulgarian).

6. Levit K, Janda V. Manual therapy. Sofia: MF; 1981: 365-377; 313-319 (in Bulgarian).

7. Milanov Iv. Neurology textbook. Medicine and Sports; 2012: 78-478 (in Bulgarian).

8. Popelyanskiy J. Ortopedic Neurology (vertebroneurology). Medpress-info, 2011 - 245. Bulgarian.

9. Riazkova M Kirova I. Physical Therapy - general and special part: Arso, 2002, c 19-50, 206-208. Bulgarian.

10. Sheytanov J Osteoarthritis: Information Center of Medicine, Sofia, 1996. Bulgarian.

11. Ahn T.J. , Lee S.H., Choi G, Ahn Y., Liu W.C.,. Kim H.J, et al. Effect of intervertebral disk degeneration on spinal stenosis during magnetic resonance imaging with axial loading Neurol Med Chir, 49 (2009), pp. 242-247. 
Mariyana Mihajlova, Silviya Filkova,Vesselina Michaleva

12. Brox JI, Storheim K, Grotle M, Tveito TH, et al. Evidence-informed management of chronic low back pain with back schools, brief education, and fear-avoidance training.Spine J. 2008 Jan-Feb; 8(1):28-39.

13. De los Reyes GC, Koda RT, Lien EJ. Glucosamin and chondroitin sulfates in the treatment of osteoarthritis: a survey. Prog Drug Res. 2000;55:81-103.

14. Furlan AD, Brosseau L, Welch V, Wong J. Massage for low back pain (Updated Cochrane Review). In: The Cochrane Library, Issue 3, 2004.

15. Gooyers C.E., McMillan R.D., Howarth S.J., Callaghan J.P. The impact of posture and prolonged cyclic compressive loading on vertebral joint mechanics.Spine (Phila Pa 1976). 2012 Aug 1;37(17): E1023-9.

16. Hadjipavlou AG, Tzermiadianos MN, Bogduk N, Zindrick MR (2008).The pathophysiology of disk degeneration: a critical review. J Bone Joint Surg Br 90: $1261-1270$

17. Halpern M. Prevention of low back pain: basic ergonomics in the workplace and the clinic.BaillieresClinRheumatol. 1992 Oct;6(3):705-30.

18. Hemmilä HM. Quality of life and cost of care of back pain patients in Finnish general practice. Spine (Phila Pa 1976) 2002 Mar 15; 27(6): 647-53.

19. Hoffman BM, Papas RK, Chatkoff DK, Kerns RD. Meta-analysis of psychological interventions for chronic low back pain. Health Psychol. 2007;26:1-9.

20. Hoogendoorn WE, van Poppel MNM, Bongers PM, Koes BW, Bouter LM. Systemic review of psychosocial factors at work and private life as risk factors for back pain. Spine 2000; 25: 2114-25. 8. Linton SJ. A review of psychological risk factors in back and neck pain. Spine 2000; 25: 1148-56.

21. Hoy D1, Brooks P, Blyth F, Buchbinder R .The Epidemiology of low back pain. Best Pract Res ClinRheumatol. 2010 Dec;24(6):769-81.

22. Kovacs FM, Abraira V, Pena A, Martin-Rodriguez JG, Sanchez-Vera M, Ferrer E, Ruano D, Guillen P, Gestoso M, Muriel A, Zamora J, Gil, de Real MT, Mufraqqi N. Effect of firmness of mattress on chronic non-specific low-back pain: Randomised, double-blind, controlled, multicentre trial, Lancet.2003; 362 (9396): 1599-1604.

23. Lambeek L, van Tulder M, Swinkels I, Koppes L et al. The trend in total cost of back pain in The Netherlands in the period 2002 to 2007. Spine. 2011; 36: 1050-1058.
24. McAlindon TE, La Valley MP, Gulin JP, Felson DT Glucosamine and chondroitin for treatment of osteoarthritis. A systematic Quality assessment and meta analysis. JAMA. 2000;283:1469-1475.

25. Neumann DA. Kinesiology of the musculoskeletal system.Foundations for rehabilitation. Mosby, Inc., an affiliate of Elsevier Inc; 2010.

26. Parreira P, Heymans MW, van Tulder MW, Esmail R, Koes BW, Poquet N, Lin C, Maher C. Back schools for chronic non-specific low back pain.Cochrane Database of Systematic Reviews .2015; 5.

27. Raj PP. Intervertebral discs: Anatomy-Physiology, Pathophysiology-ness. Pain Pract. 2008; 8: 18-44.

28. Shiri R, Karppinen J, Leino-Arjas P, Solovieva S, Viikari-JunturaE.The association between smoking and low back pain: a meta-analysis. Am J Med. 2010; 123: 87.

29. Smith, LJ, Nerurkar NL, Choi KS, Harfe BD, Elliott DM. Degeneration and regeneration of the intervertebral disc: lessons from development. Dis Model Mech. 2011; 31-41.

30. Solovieva S, Lohiniva J, Leino-Arjas P, et al. COL9A3 gene polymorphism and obesity in intervertebral disc degeneration of the lumbar spine: evidence of gene-environment interaction. Spine (Phila Pa 1976). 2002; 27:2691-2696.

31. Teraguchi M, Yoshimura N, Hashizume H, et al. Prevalence and distribution of intervertebral disc degeneration over the entire spine in a populationbased cohort: the Wakayama Spine Study. Osteoarthritis and Cartilage.2014: 104-110.

32. Tilbrook HE, Cox H, Hewitt CE, Kang'ombe AR et al. Yoga for chronic low back pain: a randomized trial. Ann Intern Med. 2011; 155:569.

33. Unlu, Z, Tasci S, Tarhan S, Pabuscu Y, Islak S. Comparison of 3 physical therapy modalities for acute pain in lumbar disc herniation measured by clinical evaluation and magnetic resonance imaging. J. Manipulative PhysiolTher. 2008; 31(3): 191-198.

34. van Blitterswijk W, van de Nes J, WuismanP. Glucosamine and chondroitin sulfate supplementation to treat symptomatic disc degeneration: Biochemical rationale and case report. BMC Complement Altern Med. 2003; 3: 2.

35. vanMiddelkoop M, Rubinstein SM, Verhagen AP et al. Exercise therapy for chronic nonspecific lowback pain. Best Pract Res ClinRheumatol. 2010; 24:193. 
36. Waddell G, Burton AK. Concepts of rehabilitation for the management of low back pain. Best Prac Res. Clin. Rheumatol. 2005; 19 (4): 655-670.

37. Wang DL, Jiang SD, Dai LY. Biologic response of the intervertebral disc to static and dynamic compression in vitro. Spine. 2007; 32:2521-8.

38. Wang Y, Videman T, Battie MC. Issls prize winner: lumbar vertebral endplate lesions associations with disc degeneration and back pain history. Spine. 2012;37:1490-1496. 